Research Article

\title{
Preparation and Kinetic Studies of Cross-Linked Chitosan Beads Using Dual Crosslinkers of Tripolyphosphate and Epichlorohydrin for Adsorption of Methyl Orange
}

\author{
Akhmad Sabarudin $\mathbb{D}^{1}$ and Armeida D. R. Madjid $\mathbb{D}^{2}$ \\ ${ }^{1}$ Department of Chemistry, Faculty of Science, Brawijaya University, Malang 65145, Indonesia \\ ${ }^{2}$ Department of Chemistry, Faculty of Science and Technology, State Islamic University of Maulana Malik Ibrahim, \\ Malang 65145, Indonesia \\ Correspondence should be addressed to Akhmad Sabarudin; sabarjpn@gmail.com
}

Received 20 November 2020; Revised 26 January 2021; Accepted 4 February 2021; Published 17 February 2021

Academic Editor: Ghadir A. El-Chaghaby

Copyright (c) 2021 Akhmad Sabarudin and Armeida D. R. Madjid. This is an open access article distributed under the Creative Commons Attribution License, which permits unrestricted use, distribution, and reproduction in any medium, provided the original work is properly cited.

\begin{abstract}
Preparation of cross-linked chitosan beads using dual crosslinkers of tripolyphosphate (TPP) and epichlorohydrin (ECH) for the adsorption and kinetic studies of methyl orange (MO) had been carried out. FTIR spectra showed that TPP could act as the protecting agent of the $\mathrm{NH}_{2}$ group of chitosan and $\mathrm{ECH}$ reacted with the primary hydroxyl group of chitosan. Various concentrations of TPP, ECH, and immersing time in the TPP solution for bead formation were studied. The effect of $\mathrm{pH}$ and kinetics of adsorption were investigated to define the mechanism of adsorption and rate-limiting step. As a result, $\mathrm{pH} 3,10 \%$ (w/v) TPP, $5 \%(\mathrm{v} / \mathrm{v}) \mathrm{ECH}$, and $12 \mathrm{~h}$ immersing time in TPP were selected as the optimum conditions for preparing the beads as indicated by the highest adsorption amount of MO. The cross-linked chitosan beads' adsorption capacity for MO under optimum condition was found to be $79.55 \mathrm{mg} / \mathrm{g}$ with the adsorption rate constant $(k)$ of $1.29 \times 10^{-3} / \mathrm{min}$. Furthermore, it was found that a low concentration of ECH could maintain the stability of chitosan in acidic conditions, whereas the concentration of TPP and immersing time controlled pore size and morphology of chitosan beads. The mechanism of adsorption of MO was controlled by the pore and rigidity of cross-linked chitosan beads. Bulk diffusion acted as a rate-limiting step, and a high concentration of MO inhibited diffusion and adsorption itself.
\end{abstract}

\section{Introduction}

Methyl orange (MO) is an azo dye widely used as a coloring agent and indicator in the titration method. Methyl orange is not toxic, but it can be hypersensitivity and allergy triggers [1]. Dyes reduce sunlight penetration in water, disturb the photosynthesis process, and lessen oxygen content. The most popular approaches for dye removal are photocatalytic degradation [2,3] and adsorption $[4,5]$ methods. Although photodegradation methods using nanostructured materials [6] and nanocomposites [7] have developed rapidly, however, adsorption method remains in popularity due to its benefit that it can prevent the production of other toxic substances [8-10]. Furthermore, the toxicity of dyes will not affect the adsorption process. The adsorption method is a simple operation and easy to modify adsorbents to enhance their adsorption capacity [11]. Some materials frequently used as the adsorbent for metallic and nonmetallic compounds are natural biomass, which includes cellulose, rice husk, and other bioadsorbents [12, 13], activated and modified activated carbons $[14,15]$, and waste materials $[16,17]$.

Chitosan, derived from the shells of shrimp and other sea crustaceans, is the natural adsorbent material classified with high adsorption capacity and available abundantly $[11,18]$. Chitosan can be modified physically or chemically to improve its stability. Physical modification of chitosan into the bead by employing tripolyphosphate (TPP) as the ionic crosslinker resulted in more rigid and stable drying processes. These beads would shrink, harden, and would not 
turn into flake [19]. However, chitosan is unstable in acids indicated by a complete solubility in acetic acid and partially dissolve in concentrated nitric acid and hydrochloric acid. For solving this problem, chitosan must be chemically crosslinked to be applied in a wide $\mathrm{pH}$ range [20-22], and it can be further functionalized with aliphatic $[23,24]$ and aromatic [25-27] moieties for more specific adsorption-desorption applications. In comparison to ethylene glycol diglycidyl ether (EGDE) [21-27], epichlorohydrin (ECH) seems to be the best option choice as a chemically bonding crosslinker, which is more appropriate for a large molecule like methyl orange (MO) [28].

Chitosan, a deacetylated form of chitin, has the functional group amine $\left(-\mathrm{NH}_{2}\right)$ and hydroxyl $\left(\mathrm{OH}^{-}\right)$as affinity centers [29]. In the acidic region, the amine $\left(\mathrm{NH}_{2}\right)$ group will be protonated into $\mathrm{NH}_{3}{ }^{+}$and interact with azo dyes. As a crosslinker, epichlorohydrin (ECH) is easily reacted with the $\mathrm{NH}_{2}$ group, resulting in lower adsorption capacity of chitosan $[30,31]$. Tripolyphospate (TPP) can be applied as the double agents for beads formation and $\mathrm{NH}_{2}$ group protector. For the modification of chitosan, TPP must be reacted first, followed by adding ECH for a cross-linking reaction via the primary hydroxyl group of chitosan. The addition of concentrate ECH $[32,33]$ or base ECH solution $[1,19]$ should be avoided because those would ruin beads and loose TPP from chitosan. In base condition, chitosan is still in the deprotonated form, and TPP would compete with hydroxyl $\left(\mathrm{OH}^{-}\right)$ to link with chitosan [34].

Adsorption is a process of concentration migration from one phase to another. There are many approaches and models for the adsorption evaluation process, such as equilibrium isotherm models, kinetics models, or thermochemistry models $[5,35]$. Each method used its assumption to interpret the relationship between time and the reduction of adsorbate concentration, which migrates into the adsorbent. The assumption was mostly dependent on adsorbent capacity or the ability of the adsorbent to trap adsorbate inside. Kinetic models are methods frequently used to evaluate the adsorption process. Pseudo-first-order (Lagergren models), pseudo-second-order (Ho and McKay Model), and Intraparticle Diffusion (Weber and Morris Model) were several common kinetic models [18, 19].

Usually, ECH as a crosslinker is reacted with the amine group of chitosan resulting in a considerable reduction of chitosan's adsorption capacity. Accordingly, in this work, a different strategy using a dual crosslinker as shown in Figure 1 was applied in regard to the adsorption capacity of chitosan. Firstly, chitosan was modified by adding TPP as an ionic crosslinker to form spherical beads and to protect its amine group. Secondly, the primary hydroxyl group of chitosan beads was reacted with $\mathrm{ECH}$ via the opening-ring reaction of its epoxide group. In the final step, TPP was released by conditioning the beads at $\mathrm{pH} \geq 10$, resulting in an un-protected amine $\left(\mathrm{NH}_{2}\right)$ group of chitosan, which provides high sorption capacity and is a very reactive adsorbent's active site. The produced cross-linked chitosan beads were characterized using FTIR and SEM. Adsorption evaluation was carried out through the removal of methyl orange (MO) using the batch method. The adsorption mechanism was investigated by varying the $\mathrm{pH}$ of the $\mathrm{MO}$ solution and contact time/adsorption time. Furthermore, the kinetics models were studied using the adsorption capacity active site adsorbent model and reduction of adsorbate concentration in the bulk solution (fractional time method).

\section{Materials and Methods}

2.1. Materials. Chitosan, epichlorohydrin (ECH, 99\%), sodium tripolyphospate (TPP), methyl orange (MO), hydrochloric acid $(\mathrm{HCl}, 37 \%)$, and sodium hydroxide $(\mathrm{NaOH})$ were purchased from Sigma-Aldrich (Singapore). All materials were of analytical grades except sodium TPP (Technical Grade, 85\%).

2.2. Instrumentations. The amount of $\mathrm{MO}$ adsorbed was measured using a Genesys 10S UV-Vis Spectrophotometer at the wavelength of $464 \mathrm{~nm}$. SEM analysis for morphology assessment of the resulted cross-linked chitosan bead was performed using Hitachi TM3000. The Shimadzu FTIR 8400 was employed for functional group characterization.

2.3. Preparation of Cross-Linked Chitosan Beads. One Gram of chitosan was dissolved in $100 \mathrm{ml}$ acetic acid 5\% (v/v) and left overnight. Then, $5 \mathrm{ml}$ chitosan solution dropped into TPP (1\%, 5\%, 10\%, and 15\% w/v) using a syringe and immersed at various time conditions $(1,3,6,12$, and $24 \mathrm{~h})$ and filtered. Chitosan beads were added to ECH solution in distilled water $(1 \%, 2.5 \%$, and $5 \% \mathrm{v} / \mathrm{v})$ and heated for $2 \mathrm{~h}$ at $50-60^{\circ} \mathrm{C}$ while stirring. After the cross-linking process, $\mathrm{NaOH}$ was added to raise $\mathrm{pH} \geq 10$ and left to stand for an hour. Then, cross-linked chitosan beads were filtered, washed with distilled water and ethanol, and dried at $105^{\circ} \mathrm{C}$ until constant weight. FTIR was used to confirm the success of the cross-linked chitosan bead preparation by identifying the specific binding group of chitosan with TPP and ECH.

2.4. Adsorption of Methyl Orange (MO). 0.02 gram of crosslinked chitosan beads was used for the adsorption of methyl orange $(50 \mathrm{~mL}$ and $20 \mathrm{ppm})$ by a batchwise method for $2 \mathrm{~h}$ and a shaking rate of $100 \mathrm{rpm}$. The effect of $\mathrm{pH}$ was studied by varying the acidity of methyl orange in the range of $\mathrm{pH}$ $2-8$. The $\mathrm{pH}$ were adjusted by the addition of $\mathrm{HCl}$ or $\mathrm{NaOH}$ solution. For adsorption kinetics investigation, $100 \mathrm{~mL}$ of methyl orange solution was adjusted to optimum $\mathrm{pH}$ and then stirred for $24 \mathrm{~h}$. The stirring was halted at an appropriate time interval, and several aliquots were taken from the supernatant using a micropipette. An aliquot was adjusted to $\mathrm{pH} 7$ then diluted to adequate volume for UV measurement at $\lambda 464 \mathrm{~nm}$. An amount of methyl orange adsorbed was calculated according to the following equation:

$$
q=\frac{\left(C_{0}-C_{e}\right) V}{m}
$$

where $q$ is the amount of methyl orange adsorbed by crosslinked chitosan beads $(\mathrm{mg} / \mathrm{g})$ and $\mathrm{C}_{0}$ and $C_{e}$ are the methyl 

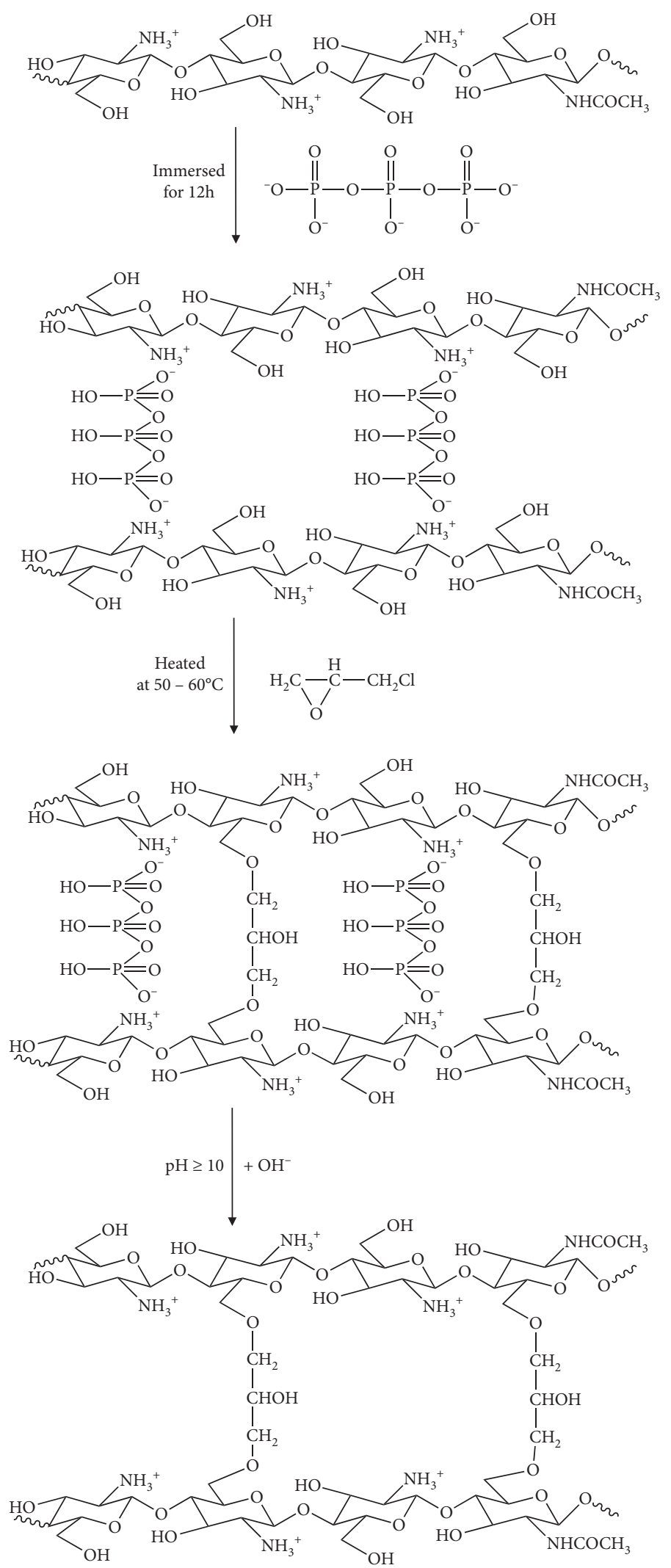

FIGURE 1: Reaction steps for the preparation of cross-linked chitosan beads. 
orange concentrations ( $\mathrm{mg} / \mathrm{L})$, respectively. $V$ is the volume of the solution $(L)$, and $m$ is the mass of the adsorbent used.

\section{Results and Discussion}

3.1. Preparation and Characterization of the Cross-Linked Chitosan Bead. Cross-linked chitosan beads were prepared by dropping chitosan solution into TPP to protect the $\mathrm{NH}_{2}$ group of chitosan and to form spherical beads. Then, ECH was reacted with the primary hydroxyl group of chitosan to improve the chemical stability of chitosan, followed by removing TPP from the $\mathrm{NH}_{2}$ group chitosan to improve the adsorption capacity of the resulted beads. To confirm the successful reactions, the products were characterized using FTIR, and the peak profiles were compared between the original chitosan and cross-linked chitosan beads, as shown in Figure 2. It was found that there was a declined intensity in $3400 \mathrm{~cm}^{-1}$, confirming the interaction of the $\mathrm{OH}^{-}$group in chitosan with ECH. Additionally, there was a declined intensity in $1200-1250 \mathrm{~cm}^{-1}$, indicating ECH's interaction with the $\mathrm{NH}_{2}$ group in chitosan. As the purpose of adding TPP in the preparation step was to prevent interaction of $\mathrm{NH}_{2}$ with ECH, however, FTIR confirmed that a part of $\mathrm{NH}_{2}$ is still linked with ECH. It means that TPP is unable to protect the $\mathrm{NH}_{2}$ group of chitosan completely, although some peaks at $1650 \mathrm{~cm}^{-1}, 1541 \mathrm{~cm}^{-1}$, and $1151 \mathrm{~cm}^{-1}$ confirmed the interaction between $\mathrm{NH}_{2}$ of chitosan and TPP [36].

For the preparation of cross-linked chitosan beads, several parameters involving TPP concentration, immersing time of the bead in TPP, and ECH concentration were optimized. The effects of those parameters were evaluated by MO's adsorption onto cross-linked chitosan beads, as shown in Figure 3. It was found that TPP concentration affected effective porosity, whereas immersing time in TPP modified pore morphology as confirmed by the SEM micrograph (Figure 4).

At similar $\mathrm{ECH}$ concentrations (5\%), it was found that a higher concentration of TPP and longer immersing time resulted in smaller pore sizes of beads and smoother surface morphology. Intermolecular and intramolecular bonds seem responsible for the link between TPP and chitosan. At a higher concentration of TPP, pore formation (intermolecular bond) occurred more effectively, whereas the intramolecular bond started forming (Figures 4(a)-4(c)). Intramolecular links caused beads to become more rigid and harder. At a longer immersing time in TPP, beads' morphology was smoother due to increment intramolecular bond formed (Figures 4(c)-4(d)). An appropriate proportion of intermolecular and intramolecular bonds in beads affected MO's adsorption onto cross-linked chitosan beads. $\mathrm{ECH}$, as a crosslinker, is aimed to improve the chemical stability of chitosan beads in acid. So, the adsorption can be performed in acid conditions without any deterioration. From these optimization steps, cross-linked chitosan beads made by $12 \mathrm{~h}$ immersing in TPP 10\% (w/v) with ECH 5\% (v/ $\mathrm{v})$ showed the best results as indicated by the highest amount of the adsorbed MO.
3.2. Adsorption of MO onto the Cross-Linked Chitosan Bead. The acidity $(\mathrm{pH})$ strongly affects the adsorption of MO onto cross-linked chitosan beads. Figure 5 exhibits the effect of $\mathrm{pH}$ toward the amount of $\mathrm{MO}$ adsorbed from $\mathrm{pH} 2$ to 8 . The highest amount of $\mathrm{MO}$ adsorbed was achieved at $\mathrm{pH} 3$. Then, along with the increment of $\mathrm{pH}$, the amount of $\mathrm{MO}$ adsorbed decreased. $\mathrm{pH}$ affected the form of adsorbate (MO) and the protonation of the $\mathrm{NH}_{2}$ group of chitosan. Methyl orange/ MO (pKa 3.4) exists in the form of a zwitterion in acidic conditions and an anion in the base solution [37], whereas the $\mathrm{NH}_{2}$ group of chitosan ( $\mathrm{pKa} 6.5$ ) protonates into $-\mathrm{NH}_{3}{ }^{+}$ at the acidic condition [21-23].

Because $\mathrm{MO}$ forms zwitterions and $-\mathrm{NH}_{2}$ of chitosan were protonated into $-\mathrm{NH}_{3}{ }^{+}$at $\mathrm{pH} 3$, the repulsion between positive charge in $\mathrm{MO}$ and $\mathrm{NH}_{3}{ }^{+}$occurred, resulting in low adsorption amounts of MO. However, as shown in Figure 5, the highest amount of $\mathrm{MO}$ was achieved at this $\mathrm{pH}$. This condition revealed the role of TPP in adsorption diffusion. At $\mathrm{pH}$ 3, TPP exists in the form of $\mathrm{H}_{2} \mathrm{P}_{3} \mathrm{O}_{10}{ }^{3-}$ where its two negative charges interact with protonated chitosan while the remaining one reacts with positively charged MO. This adsorption mechanism is illustrated in Figure 6. Modification of chitosan using ECH and TPP can extend chitosan application in the broad range of $\mathrm{pH}$ conditions. It was indicated by the cross-linked chitosan beads' excellent stability at a range of the examined $\mathrm{pH}(2-8)$.

The cross-linked chitosan bead's adsorption capacity was examined by equilibrating an appropriate amount of the bead with the excess amount of MO solution under optimum conditions. As shown in Figure 7, it was found that the adsorption capacity of the cross-linked chitosan bead towards MO was estimated to be $79.55 \mathrm{mg} / \mathrm{g}$. Besides the simple synthesis procedure, compared to other adsorbents for the removal of $\mathrm{MO}$, the cross-linked chitosan bead prepared in this work exhibits comparable and/or higher adsorption capacity as shown in Table 1. Accordingly, these beads provide the good potential to be used as an adsorbent for the removal of $\mathrm{MO}$ and other dyes in the environmental samples.

3.3. Adsorption Kinetics of MO onto the Cross-Linked Chitosan Bead. Adsorption steps of MO onto the cross-linked chitosan bead were considered to involve four steps, as illustrated in Figure 8:

(a) Bulk diffusion, mass transfer of adsorbate from bulk solution into the outer Helmholtz plane

(b) Film diffusion, adsorbate shift from the outer Helmholtz plane into the inner Helmholtz plane

(c) Intraparticle diffusion, adsorbate transfer into the affinity site of the adsorbent

(d) Adsorption process, adsorbate trap in the adsorbent chemically or physically

One of these steps acts as a rate-limiting step. The reaction rate of adsorption was investigated by using pseudofirst-order, pseudo-second-order, and interparticle diffusion models. Pseudo-first-order and pseudo-second-order 


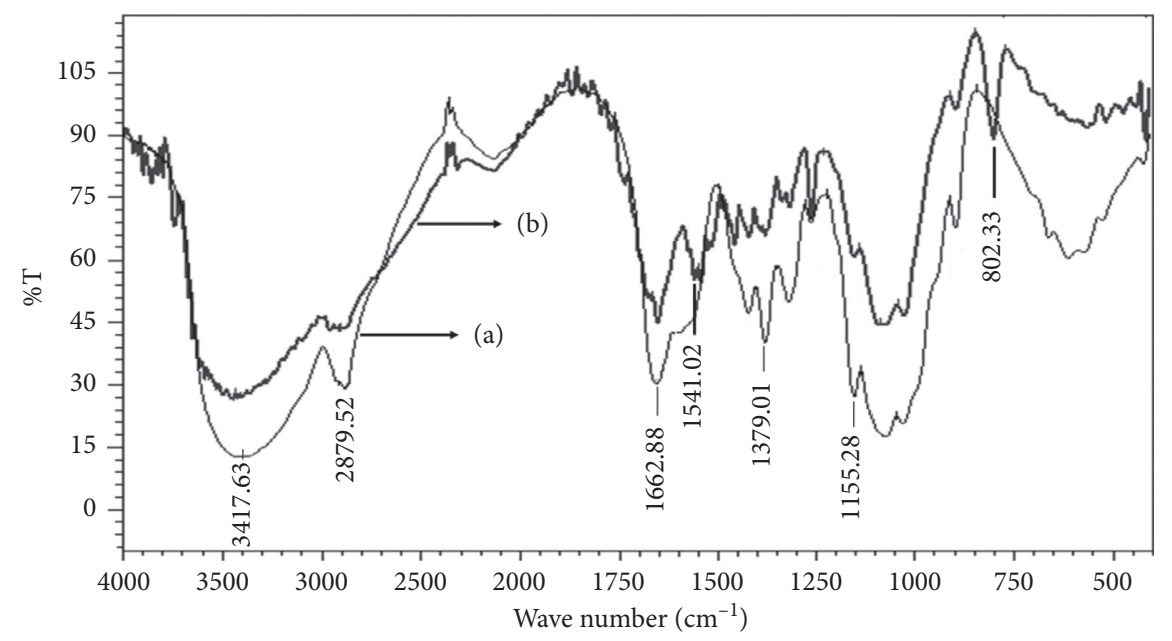

FIgURE 2: IR spectra of chitosan (a) and cross-linked chitosan beads (b).

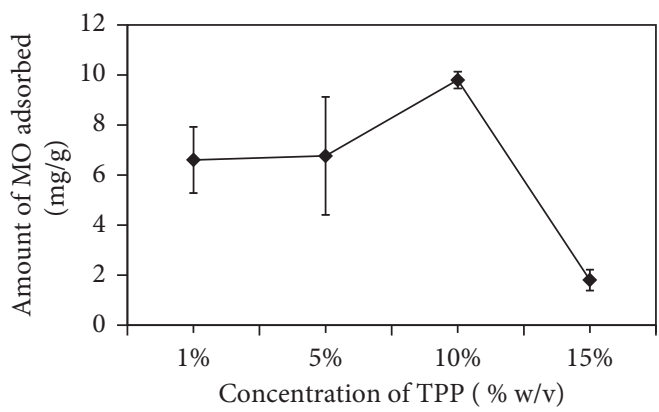

(a)

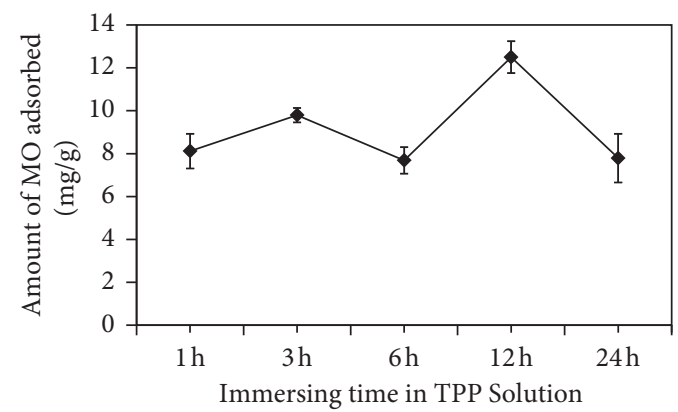

(b)

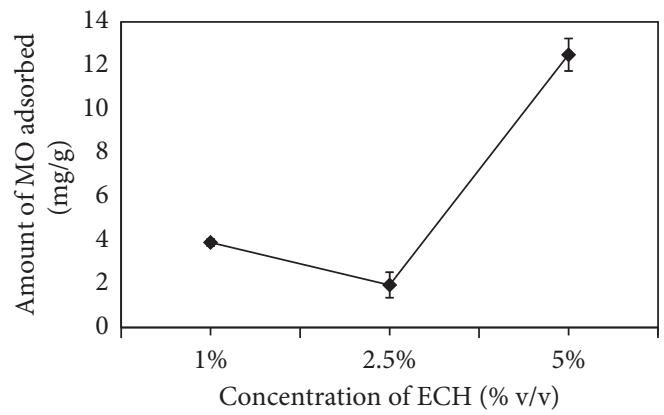

(c)

FIgURE 3: Effect of TPP concentration at conditions of $12 \mathrm{~h}$ immersing time and ECH $5 \%(\mathrm{v} / \mathrm{v})(\mathrm{a})$, immersing time of chitosan in TPP solution at conditions of TPP $10 \%(\mathrm{w} / \mathrm{v})$ and ECH 5\% (v/v) (b), and concentration of ECH at conditions of $12 \mathrm{~h}$ immersing time in TPP $10 \%$ (w/v) (c) for the preparation of the cross-linked chitosan beads. Sample: $50 \mathrm{~mL}$ methyl orange $20 \mathrm{ppm}$; cross-linked chitosan beads mass: $0.02 \mathrm{~g}$; stirring rate $=100 \mathrm{rpm} ; \mathrm{pH} 4$.

models were based on the active site of an adsorbent. Intraparticle diffusion models reconstructed mass transfer of the adsorbate from the bulk solution into the adsorbent. The adsorption process is controlled by the adsorbent's capacity and the concentration of adsorbate. The adsorbate concentration is the driving force of mass transfer from the bulk solution into an adsorbent's inner. Based on the adsorbate concentration, the order of reaction should be determined firstly by calculating the reaction rate. The order reaction was determined using a fractional time method.
3.3.1. Active Site Capacity Kinetics Model. The pseudo-firstorder kinetics model is given by the following equation:

$$
\log \left(\frac{q_{e}}{q_{e}-q_{t}}\right)=\frac{k_{1}}{2.303} t
$$

where $q_{e}$ and $q_{t}$ are the amount of methyl orange adsorbed in equilibrium and at $t$ and $k_{1}$ is a rate constant of the pseudofirst-order kinetic model $\left(\mathrm{min}^{-1}\right)$. The straight-line plot log $\left(q_{e}\right.$ and $q_{t}$ ) against $t$ was used to determine $k_{1}$ and $r$, correlation coefficient, which can be seen in Figure 9(a). 


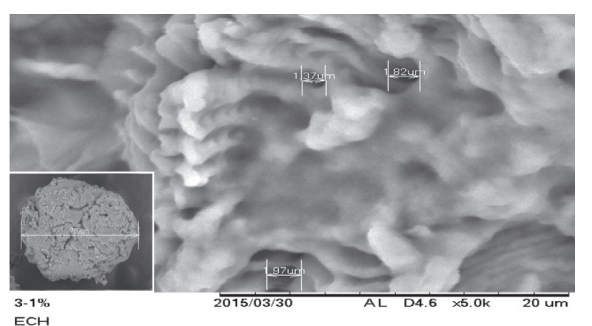

(a)

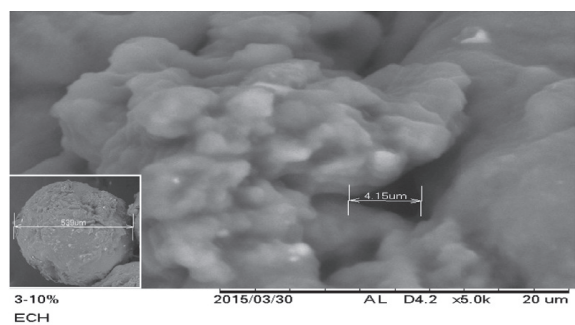

(c)

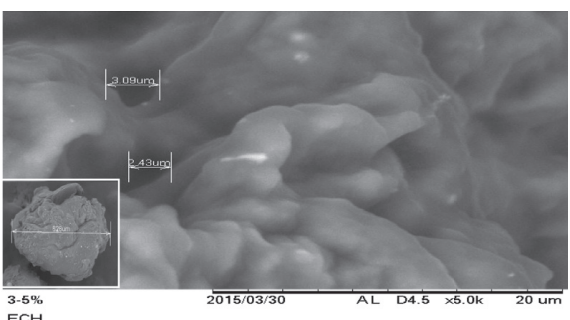

(b)

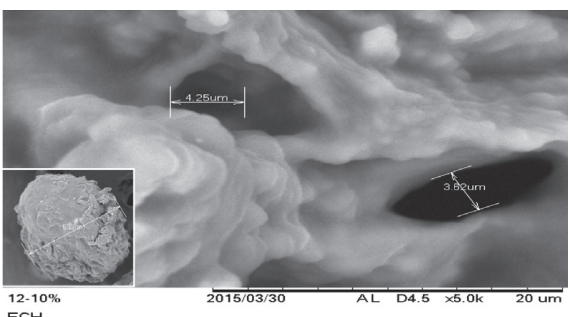

(d)

FIGURE 4: SEM images of cross-linked chitosan beads using 5\% (v/v) ECH immersed in TPP $1 \%$ for $3 \mathrm{~h}(\mathrm{a})$, TPP $5 \%$ for $3 \mathrm{~h}$ (b), TPP $10 \%$ for $3 \mathrm{~h}(\mathrm{c})$, and TPP $10 \%$ for $12 \mathrm{~h}$ (d) with magnification of 5000x. Inset pictures are SEM images of the beads with a magnification of $100 \mathrm{x}$.

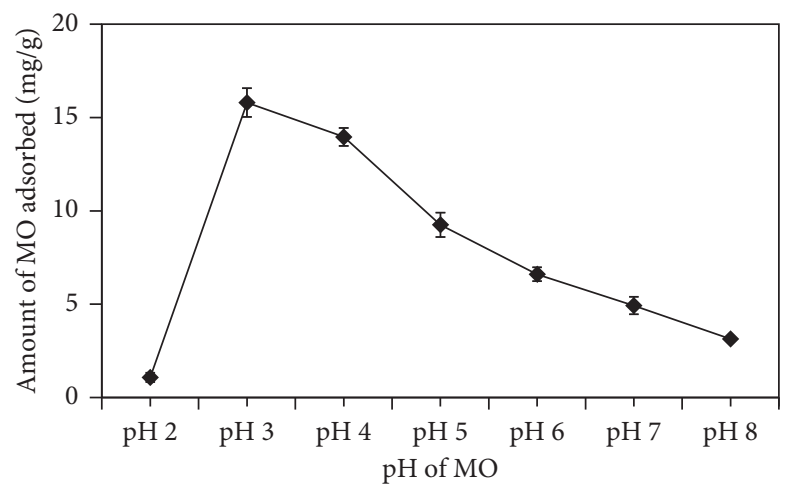

FIGURE 5: Effects of $\mathrm{pH}$ on the adsorption of MO using cross-linked chitosan beads. The bead crosslinkers are ECH 5\% immersed in TPP $10 \%$ for $12 \mathrm{~h}$; sample: $50 \mathrm{~mL}$ methyl orange $20 \mathrm{ppm}$; cross-linked chitosan bead's mass: $0.02 \mathrm{~g}$; and stirring rate $=100 \mathrm{rpm}$.

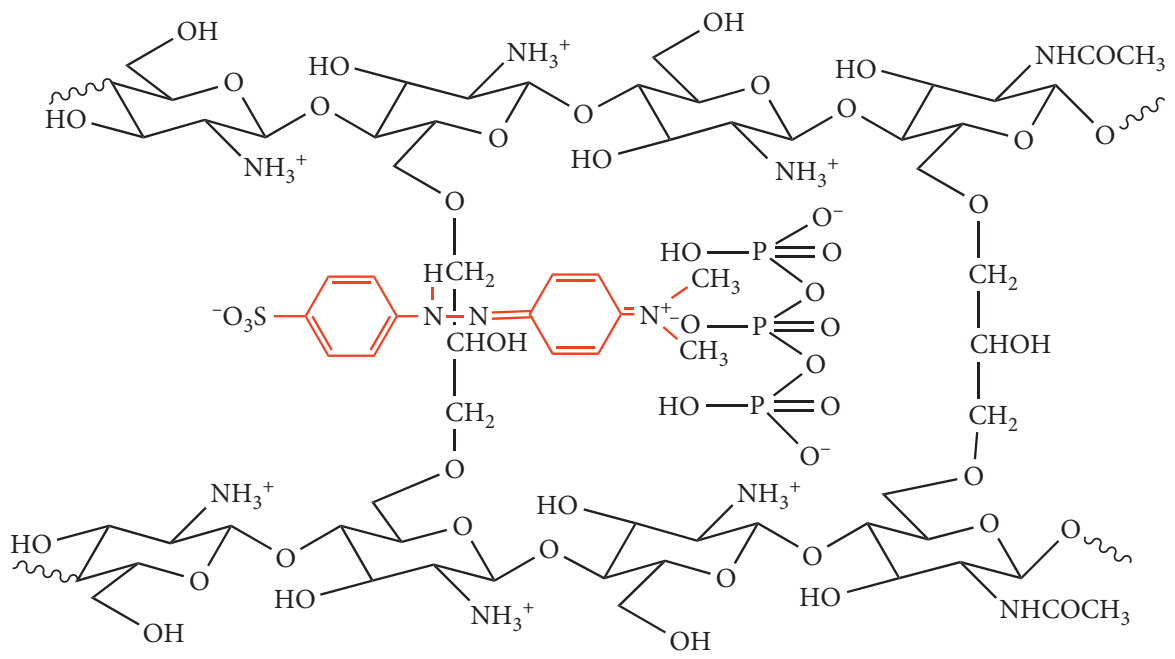

FIgURE 6: Adsorption mechanism of methyl orange onto cross-linked chitosan beads. 


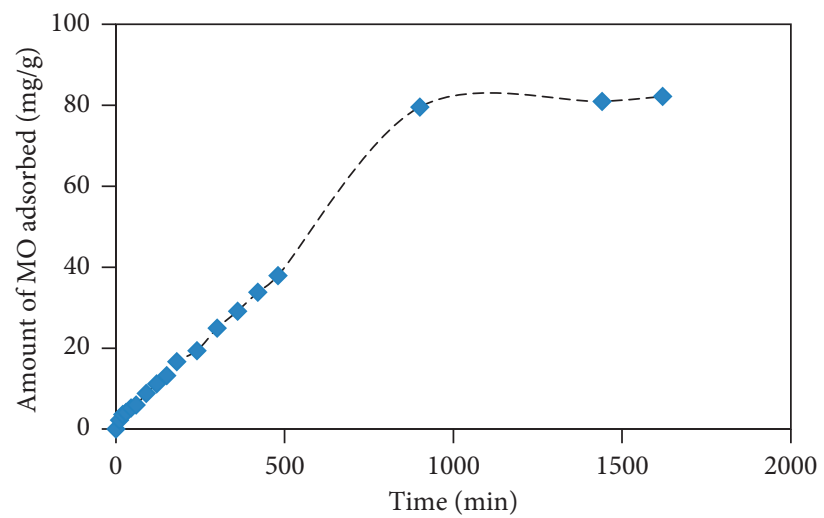

Figure 7: Effect of contact time on the adsorption of methyl orange onto cross-linked chitosan beads. Sample: $100 \mathrm{~mL}$ methyl orange $20 \mathrm{ppm}$; chitosan bead's mass: $0.02 \mathrm{~g}$; stirring rate: $100 \mathrm{rpm}$.

TABLE 1: Adsorption capacities of several adsorbents for the methyl orange adsorption.

\begin{tabular}{|c|c|c|}
\hline Adsorbent & Adsorption capacity (mg/g) & Reference \\
\hline Hollow molybdenum disulfide microspheres & 41.5 & {$[37]$} \\
\hline Polyaniline nano-adsorbent & 75.9 & {$[38]$} \\
\hline Goethite impregnated with chitosan beads & 84.0 & [39] \\
\hline$\gamma-\mathrm{Fe}_{2} \mathrm{O}_{3} / \mathrm{SiO}_{2} /$ chitosan composite & 34.3 & {$[40]$} \\
\hline Chitosan/alumina composite & 35.3 & {$[41]$} \\
\hline Hyper-cross-linked polymer & 76.9 & {$[42]$} \\
\hline Polyaniline on a glass plate & 93.0 & {$[43]$} \\
\hline Magnetic iron oxide/carbon nanocomposites & 72.7 & {$[44]$} \\
\hline Polyacrylonitrile-coated kapok hollow microtubes & 34.7 & {$[45]$} \\
\hline Magnetic chitosan enwrapping nanosized $\gamma-\mathrm{Fe}_{2} \mathrm{O}_{3}$ and multiwalled carbon nanotubes & 66.1 & {$[46]$} \\
\hline Dual crosslinker-TPP/ECH-chitosan bead & 79.5 & This work \\
\hline
\end{tabular}

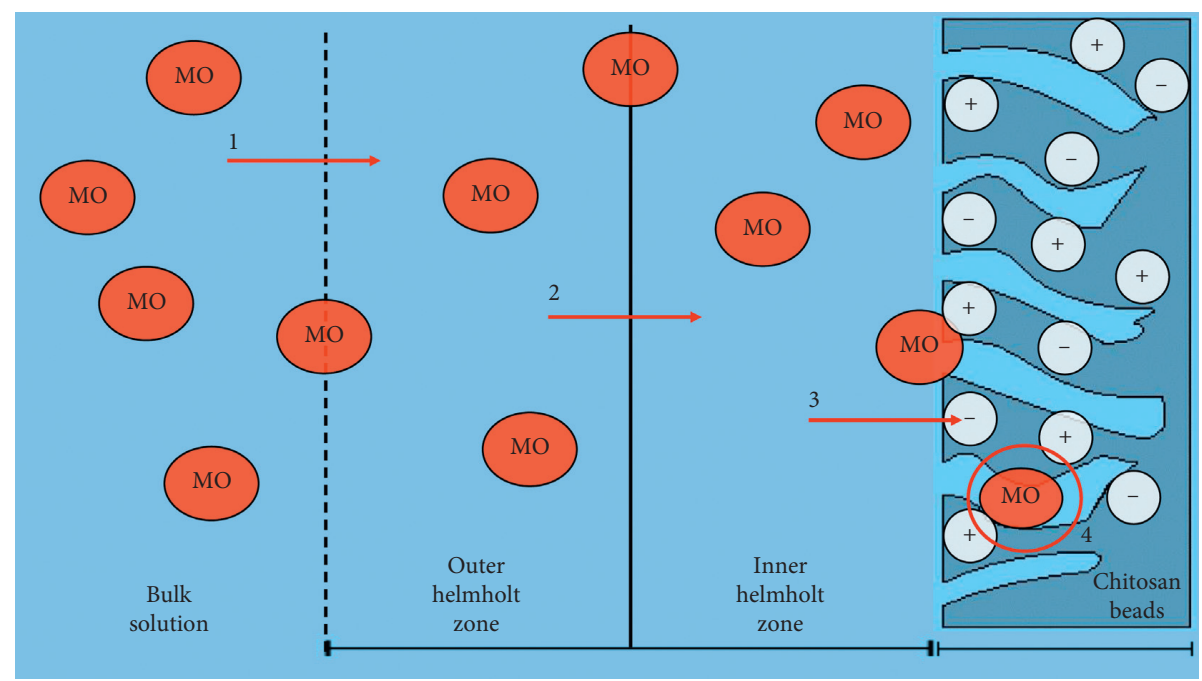

Figure 8: Diffusion steps of methyl orange from the bulk solution into cross-linked chitosan beads (1- bulk diffusion, 2- film diffusion, 3intraparticle diffusion, and 4- adsorption on chitosan beads).

The pseudo-second-order kinetic model is given in the following equation:

$$
\frac{1}{q_{e}-q_{t}}=\frac{1}{q_{e}}+k_{2} t
$$




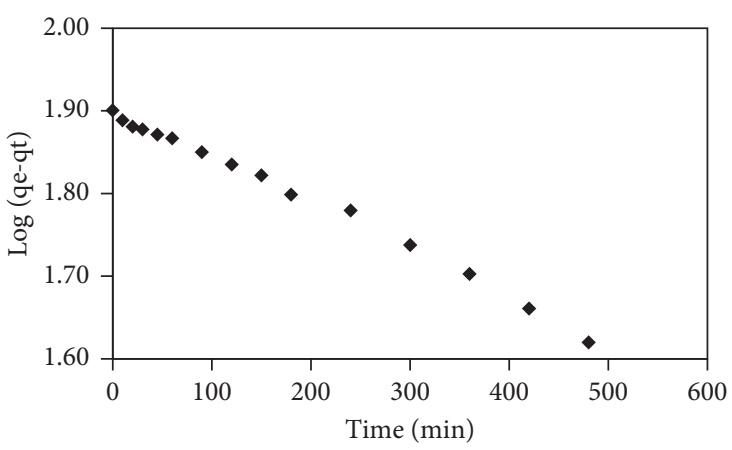

(a)

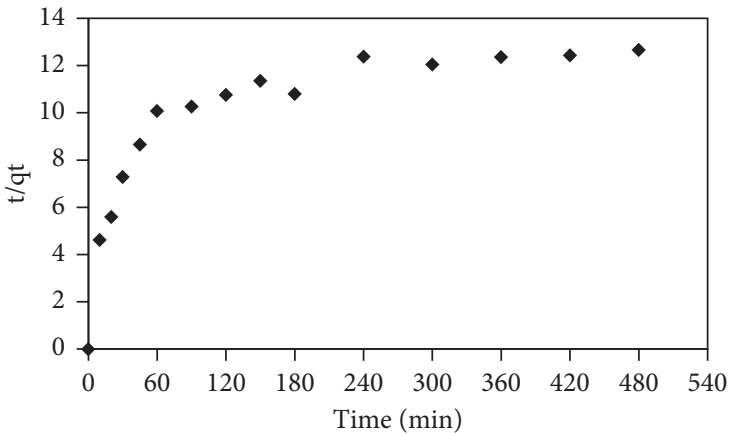

(b)

FIGURE 9: Pseudo-first-order plot (a) and pseudo-second-order plot (b) for the adsorption of MO onto cross-linked chitosan beads.

where $q_{e}$ and $q_{t}$ are the amount of methyl orange adsorbed in equilibrium and at $t$ and $k_{2}$ is a rate constant of the pseudosecond-order kinetic model $\left(\mathrm{mg} \operatorname{gram}^{-1} \mathrm{~min}^{-1}\right)$. The straight-line plot $t / q_{t}$ against $t$ was used to determine $k_{2}$ and $r$, correlation coefficient, which can be seen in Figure 9(b). The active site capacity model showed that kinetic adsorption of methyl orange onto cross-link chitosan beads fitted to pseudo-first-order $(r=0.994)$ than pseudo-secondorder $(r=0.645)$. Irreversible adsorption occurred because methyl orange (MO) was trapped in the pore of chitosan beads.

3.3.2. Intraparticle Diffusion Kinetics Model. The following equation gives the intraparticle diffusion kinetic model: where $q$ refers to the amount of methyl orange adsorbed at $t$ and $k_{i}$ is a diffusion rate $(\mathrm{mg} / \mathrm{g} \min 0.5)$. There were five linearity portions in intraparticle diffusion kinetics models. It indicated five steps that occurred in the adsorption process (Figure 10). The first step $\left(\mathrm{ki}_{1}-\downarrow\right)$ referred to bulk diffusion, $\mathrm{ki}_{2}$ (ם) related to film diffusion, $\mathrm{ki}_{3}(\boldsymbol{\Delta})$ referred to intraparticle diffusion, $\mathrm{ki}_{4}(\mathrm{l})$ associated with the adsorption step, and $\mathrm{ki}_{5}(\mathrm{)}$ referred to the equilibrium step. At the end, diffusion was getting slower due to the low concentration of methyl orange left in the solution. Figure 10 exhibits that $\mathrm{ki}_{1}$ was the slowest rate reaction. It means that the rate-limiting process was bulk diffusion.

$$
q_{t}=k_{i} t^{0.5}
$$

\subsubsection{Adsorbate Concentration Kinetics Model.} Adsorbate concentration in the solution decreased linearly at a longer contact time with adsorbent and tended to constant after equilibrium was reached as shown in Figure 11. It implies that the reduction of adsorbate concentration is proportional to the adsorption process. The fractional time method was chosen to determine the order reaction that focuses on proving that the reaction proceeds as first order or not. The order of reaction relates to the adsorption mechanism.

Fractional time is a time when concentration $\mathrm{C}([\mathrm{C}])$ becomes $\alpha$ times from initial concentration $[\mathrm{C}]_{0}$, and the

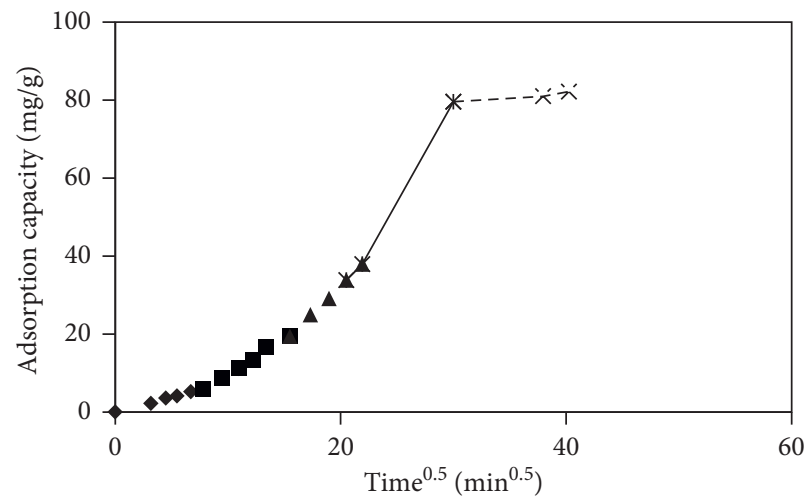

FIGURE 10: Intraparticle diffusion plot for the adsorption of methyl orange onto cross-linked chitosan beads.

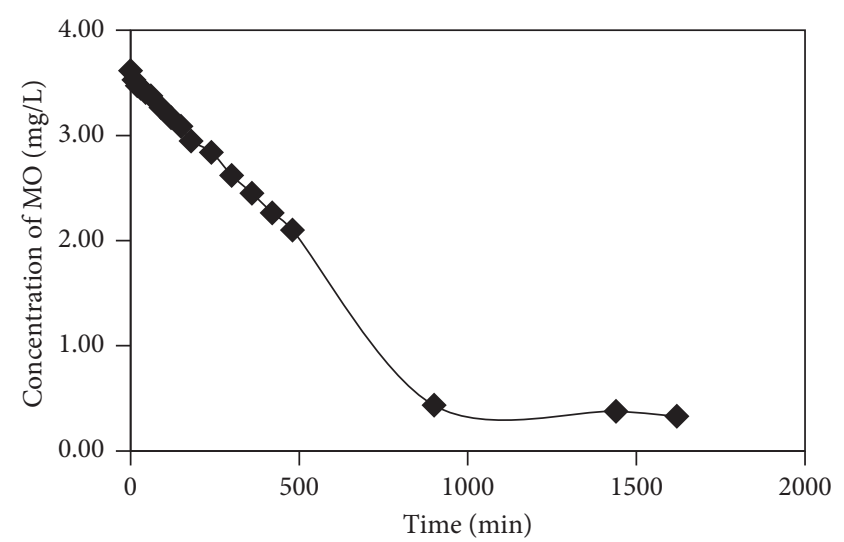

Figure 11: Effect of contact time on reducing adsorbate concentration during the adsorption of methyl orange onto cross-linked chitosan beads.

range of $\alpha$ is 0 to 1 . We assumed that the reaction was irreversible, so if $n$ (reaction order) $=1, t \alpha$ is given by the following equation [47]:

$$
t_{\alpha}=-\frac{\ln \alpha}{k_{a}}
$$

For $n \neq 1, t_{\alpha}$ is given by the following equation: 


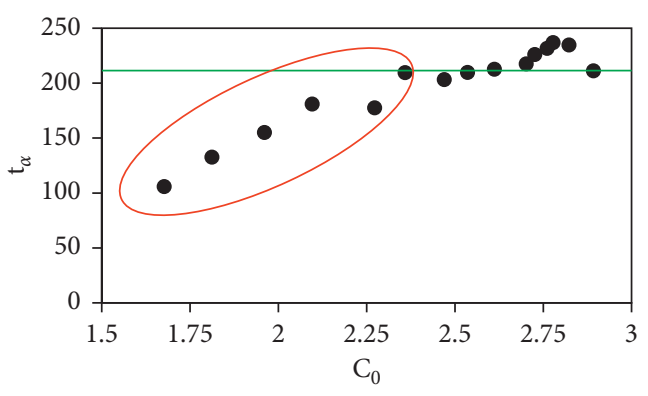

(a)

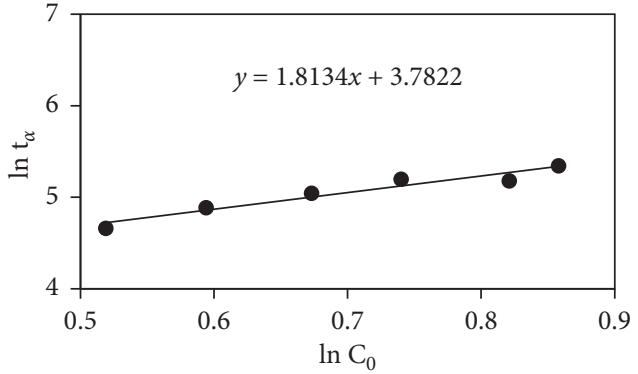

(b)

FIgURE 12: Fractional time models for $n=1$ (a) and fractional time models for $n \neq 1$ (b) for the adsorption of methyl orange onto crosslinked chitosan beads.

TABLe 2: Summary of the kinetic adsorption calculation.

\begin{tabular}{|c|c|c|c|}
\hline Kinetics model & $q_{\mathrm{e}(\mathrm{calc})}$ & $k$ & $r^{2}$ \\
\hline $\begin{array}{l}\text { Active site capacity } \\
\text { Pseudo } 1^{\text {st }} \text { order } \\
\text { Pseudo } 2^{\text {st }} \text { order }\end{array}$ & $\begin{array}{c}7.928 \times 10^{1} \mathrm{mg} / \mathrm{g} \\
7.468 \mathrm{mg} / \mathrm{g}\end{array}$ & $\begin{array}{c}1.29 \times 10^{-3} / \mathrm{min} \\
2.328 \times 10^{-5} \mathrm{~g} / \mathrm{mg} \cdot \min \end{array}$ & $\begin{array}{l}0.994 \\
0.645\end{array}$ \\
\hline $\begin{array}{l}\text { Intraparticle diffusion } \\
K_{\mathrm{i} 1} \\
K_{\mathrm{i} 2} \\
K_{\mathrm{i} 3} \\
K_{\mathrm{i} 4} \\
K_{\mathrm{i} 5}\end{array}$ & & $\begin{array}{l}0.777 \mathrm{mg} / \mathrm{g} \cdot \min ^{0.5} \\
1.782 \mathrm{mg} / \mathrm{g} \cdot \min ^{0.5} \\
2.865 \mathrm{mg} / \mathrm{g} \cdot \min ^{0.5} \\
4.930 \mathrm{mg} / \mathrm{g} \cdot \min ^{0.5} \\
0.223 \mathrm{mg} \text { g. } \min ^{0.5}\end{array}$ & $\begin{array}{l}0.994 \\
0.990 \\
0.999 \\
0.996 \\
0.934 \\
\end{array}$ \\
\hline $\begin{array}{l}\text { Fractional time } \\
n \neq 1 \\
n=1\end{array}$ & & $\begin{array}{c}9.72 \times 10^{-2} \mathrm{mg} / \mathrm{L} . \mathrm{min} \\
1.03 \times 10^{-3} / \mathrm{min}\end{array}$ & 0.933 \\
\hline
\end{tabular}

$$
t_{\alpha}=\frac{\alpha^{1-n}-1}{(n-1) k_{a}[C]_{0}^{n-1}} .
$$

Equation (6) can be converted into a linear form as follows:

$$
\ln t_{\alpha}=\frac{\ln \alpha^{n-1}-1}{(n-1) k_{a}}-(n-1) \ln [C]_{0} .
$$

Then, if we make a relation graph between $t_{\alpha}(\mathrm{min})$ with $[\mathrm{c}]_{0}(\mathrm{ppm})$ (Figure $12(\mathrm{a})$ ), it can be seen that the fractional time of each methyl orange concentration is not constant. It means that a reaction order $(n) \neq 1$. Figure 12 (a) showed two regions of kinetics which fit and unfit to the first-order reaction. The circled area was unfitted to the first-order reaction. So, recalculation of the reaction order with fractional times for the $n \neq 1$ equation must be performed. Figure 12(b) shows fractional time calculation for $n \neq$. From a straight-line plot between $\ln t_{\alpha}$ vs. $\ln C_{0}$, it was found (slope of plot equal with $-(n-1)$ that the order of the reaction was $-0.8134 \approx-1$. This result indicated a higher concentration of methyl orange (MO) would inhibit diffusion or adsorption itself.

All calculations dealing with kinetic adsorption models are summarized in Table 2. The investigation of each kinetic model showed that methyl orange (MO) adsorption onto cross-linked chitosan beads is more fit for the pseudo-first-order model than the pseudo-second-order model. Pseudo-first-order kinetic models plotted with excellent linearity $(r=0.994)$, and an amount of $q_{\mathrm{e}(\exp )}$ closed to $q_{\mathrm{e} \text { (theory). }}$ Bulk diffusion was a rate-limiting step, but methyl orange concentration could inhibit diffusion and adsorption itself.

\section{Conclusions}

The new preparation method of a cross-linked chitosan bead has been designed by adding a protective group of tripolyphospate (TPP) to prevent chemical binding between $\mathrm{NH}_{2}$ of chitosan and epichlorohydrin (ECH), which could reduce the adsorption capacity of the bead towards MO. After removing the protective group from the bead, $\mathrm{NH}_{2}$ of chitosan could freely attract the anionic dye methyl orange, resulting in an adsorption capacity of $79.55 \mathrm{mg} / \mathrm{g}$. The adsorption mechanism of MO onto the cross-linked chitosan bead occurred physically, which was controlled by the pore and rigidity of cross-linked chitosan beads.

\section{Data Availability}

All data used to support the findings of this study are available from the corresponding author upon request.

\section{Conflicts of Interest}

All authors stated that there are no conflicts of interest. 


\section{Acknowledgments}

This work was partially supported by the research grant 2020 from the Ministry and Research Technology and Higher Education of Indonesia (no. 167/SP2H/AMD/LT/DRPM/ 2020) through the scheme of PDUPT and Penelitian Dasar.

\section{References}

[1] L. Obeid, A. Bée, D. Talbot et al., "Chitosan/maghemite composite: a magsorbent for the adsorption of methyl orange," Journal of Colloid and Interface Science, vol. 410, pp. 52-58, 2013.

[2] Y. Yuan, R.-T. Guo, L.-F. Hong et al., "Recent advances and perspectives of MoS2-based materials for photocatalytic dyes degradation: a review," Colloids and Surfaces A: Physicochemical and Engineering Aspects, vol. 611, Article ID 125836, 2021.

[3] P. A. Luque, M. J. Chinchillas-Chinchillas, O. Nava et al., "Green synthesis of tin dioxide nanoparticles using Camellia sinensis and its application in photocatalytic degradation of textile dyes," Optik, vol. 229, Article ID 166259, 2021.

[4] E. A. Dil, M. Ghaedi, A. M. Ghaedi et al., "Modeling of quaternary dyes adsorption onto ZnO-NR-AC artificial neural network: analysis by derivative spectrophotometry," Journal of Industrial and Engineering Chemistry, vol. 34, pp. 186-197, 2016.

[5] F. Nekouei, S. Nekouei, I. Tyagi, and V. K. Gupta, "Kinetic, thermodynamic and isotherm studies for acid blue 129 removal from liquids using copper oxide nanoparticle-modified activated carbon as a novel adsorbent," Journal of Molecular Liquids, vol. 201, pp. 124-133, 2015.

[6] J. López, A. A. Ortíz, F. Muñoz-Muñoz et al., "Magnetic nanostructured based on cobalt-Zinc Ferrites designed for photocatalytic dye degradation," Journal of Physics and Chemistry of Solids, vol. 150, Article ID 109869, 2021.

[7] H. Mittal and M. Khanuja, "Hydrothermal in-situ synthesis of $\mathrm{MoSe}_{2}$-polypyrrole nanocomposite for efficient photocatalytic degradation of dyes under dark and visible light irradiation," Separation and Purification Technology, vol. 254, Article ID 117508, 2021.

[8] X. Sun, Y. Zhou, and X. Zheng, "Comparison of adsorption behaviors of Fe-La oxides co-loaded MgO nanosheets for the removal of methyl orange and phosphate in single and binary systems," Journal of Environmental Chemical Engineering, vol. 8, Article ID 104252, 2020.

[9] S. Hussain, M. Kamran, S. A. Khan et al., "Adsorption, kinetics and thermodynamics studies of methyl orange dye sequestration through chitosan composites films," International Journal of Biological Macromolecules, vol. 168, pp. 383-394, 2021.

[10] B. R. Babu, A. K. Parande, S. Raghu, and T. P. Kumar, "Cotton textile processing: waste generation and effluent treatment," The Journal of Cotton Science, vol. 11, pp. 141-153, 2007.

[11] G. Crini, "Non-conventional low-cost adsorbents for dye removal: a review," Bioresource Technology, vol. 97, no. 9, pp. 1061-1085, 2006.

[12] C. Feng, P. Ren, M. Huo et al., "Facile synthesis of trimethylammonium grafted cellulose foams with high capacity for selective adsorption of anionic dyes from water," Carbohydrate Polymers, vol. 241, Article ID 116369, 2020.

[13] Z. Jiang and D. Hu, "Molecular mechanism of anionic dyes adsorption on cationized rice husk cellulose from agricultural wastes," Journal of Molecular Liquids, vol. 276, pp. 105-114, 2019.

[14] S. Salem, Z. Teimouri, and A. Salem, "Fabrication of magnetic activated carbon by carbothermal functionalization of agriculture waste via microwave-assisted technique for cationic dye adsorption," Advanced Powder Technology, vol. 31, no. 10, pp. 4301-4309, 2020.

[15] A. Chowdhury, S. Kumari, A. A. Khan, M. R. Chandra, and S. Hussain, "Activated carbon loaded with Ni-Co-S nanoparticle for superior adsorption capacity of antibiotics and dye from wastewater: kinetics and isotherms," Colloids and Surfaces A: Physicochemical and Engineering Aspects, vol. 611, Article ID 125868, 2021.

[16] A. Mittal, V. Gajbe, and J. Mittal, "Removal and recovery of hazardous triphenylmethane dye, Methyl Violet through adsorption over granulated waste materials," Journal of Hazardous Materials, vol. 150, no. 2, pp. 364-375, 2008.

[17] K. Srasri, M. Thongroj, P. Chaijiraaree et al., "Recovery potential of cellulose fiber from newspaper waste: an approach on magnetic cellulose aerogel for dye adsorption material," International Journal of Biological Macromolecules, vol. 119, pp. 662-668, 2018.

[18] G. Crini and P.-M. Badot, “Application of chitosan, A natural aminopolysaccharide, for dye removal from aqueous solutions by adsorption processes using batch studies: a review of recent literature," Progress in Polymer Science, vol. 33, no. 4, pp. 399-447, 2008.

[19] M. S. Chiou and H. Y. Li, "Adsorption behavior of reactive dye in aqueous solution on chemical cross-linked chitosan beads," Chemosphere, vol. 50, no. 8, pp. 1095-1105, 2003.

[20] A.-H. Chen and Y.-Y. Huang, "Adsorption of remazol black 5 from aqueous solution by the templated crosslinked-chitosans," Journal of Hazardous Materials, vol. 177, no. 1-3, pp. 668-675, 2010.

[21] A. Sabarudin, K. Oshita, M. Oshima, and S. Motomizu, "Synthesis of chitosan resin possessing 3,4-diamino benzoic acid moiety for the collection/concentration of arsenic and selenium in water samples and their measurement by inductively coupled plasma-mass spectrometry," Analytica Chimica Acta, vol. 542, no. 2, pp. 207-215, 2005.

[22] A. Sabarudin, M. Oshima, T. Takayanagi et al., "Functionalization of chitosan with 3,4-dihydroxybenzoic acid for the adsorption/collection of uranium in water samples and its determination by inductively coupled plasma-mass spectrometry," Analytica Chimica Acta, vol. 581, no. 2, pp. 214-220, 2007.

[23] A. Sabarudin, K. Oshita, M. Oshima, and S. Motomizu, "Synthesis of cross-linked chitosan possessing N-methyl-Dglucamine moiety (CCTS-NMDG) for adsorption/concentration of boron in water samples and its accurate measurement by ICP-ms and ICP-aes," Talanta, vol. 66, no. 1, pp. 136-144, 2005.

[24] A. Sabarudin, T. Umemura, and S. Motomizu, "Chitosan functionalized with di-2-propanolamine: its application as solid phase extractant for the determination of germanium in water samples by ICP-MS," Microchemical Journal, vol. 99, no. 1, pp. 34-39, 2011.

[25] A. Sabarudin, O. Noguchi, M. Oshima, K. Higuchi, and S. Motomizu, "Application of chitosan functionalized with 3,4-dihydroxy benzoic acid moiety for on-line preconcentration and determination of trace elements in water samples," Microchimica Acta, vol. 159, no. 3-4, pp. 341-348, 2007.

[26] A. Sabarudin, N. Lenghor, M. Oshima et al., "Sequentialinjection on-line preconcentration using chitosan resin 
functionalized with 2-amino-5-hydroxy benzoic acid for the determination of trace elements in environmental water samples by inductively coupled plasma-atomic emission spectrometry," Talanta, vol. 72, no. 5, pp. 1609-1617, 2007.

[27] A. Sabarudin, M. Oshima, O. Noguchi, S. Motomizu, Y.-H. Gao, and S. Motomizu, "Functionalization of chitosan with 3-nitro-4-amino benzoic acid moiety and its application to the collection/concentration of molybdenum in environmental water samples," Talanta, vol. 73, no. 5, pp. 831-837, 2007.

[28] F. Mi, S.-S. Shyu, C.-T. Chen, and J.-Y. Lai, "Adsorption of indomethacin onto chemically modified chitosan beads," Polymer, vol. 43, no. 3, pp. 757-765, 2002.

[29] W. S. W. Ngah and S. Fatinathan, "Adsorption characterization of $\mathrm{Pb}(\mathrm{II})$ and $\mathrm{Cu}(\mathrm{II})$ ions onto chitosan-tripolyphosphate beads: kinetic, equilibrium and thermodynamic studies," Journal of Environmental Management, vol. 91, no. 4, pp. 958-969, 2010.

[30] V. L. Gonçalves, M. C. M. Laranjeira, V. T. Fávere, and R. C. Pedrosa, "Effect of crosslinking agents on chitosan microspheres in controlled release of diclofenac sodium," Polimeros, vol. 15, pp. 6-12, 2005.

[31] F.-C. Wu, R.-L. Tseng, and R.-S. Juang, "Comparative adsorption of metal and dye on flake- and bead-types of chitosans prepared from fishery wastes," Journal of Hazardous Materials, vol. 73, no. 1, pp. 63-75, 2000.

[32] A.-H. Chen, S.-C. Liu, C.-Y. Chen, and C.-Y. Chen, "Comparative adsorption of $\mathrm{Cu}(\mathrm{II}), \mathrm{Zn}(\mathrm{II})$, and $\mathrm{Pb}(\mathrm{II})$ ions in aqueous solution on the crosslinked chitosan with epichlorohydrin," Journal of Hazardous Materials, vol. 154, no. 1-3, pp. 184-191, 2008.

[33] R. Laus, T. G. Costa, B. Szpoganicz, and V. T. Fávere, “Adsorption and desorption of $\mathrm{Cu}(\mathrm{II}), \mathrm{Cd}(\mathrm{II})$ and $\mathrm{Pb}(\mathrm{II})$ ions using chitosan crosslinked with epichlorohydrin-triphosphate as the adsorbent," Journal of Hazardous Materials, vol. 183, no. 1-3, pp. 233-241, 2010.

[34] S.-T. Lee, F.-L. Mi, Y.-J. Shen, and S.-S. Shyu, "Equilibrium and kinetic studies of copper(II) ion uptake by chitosantripolyphosphate chelating resin," Polymer, vol. 42, no. 5, pp. 1879-1892, 2001.

[35] N. Mohammadi, H. Khani, V. K. Gupta, E. Amereh, and S. Agarwal, "Adsorption process of methyl orange dye onto mesoporous carbon material-kinetic and thermodynamic studies," Journal of Colloid and Interface Science, vol. 362, no. 2, pp. 457-462, 2011.

[36] D. R. Bhumkar and V. B. Pokharkar, "Studies on effect of $\mathrm{pH}$ on cross-linking of chitosan with sodium tripolyphosphate: a technical note," AAPS PharmSciTech, vol. 7, no. 2, pp. E138-E143, 2006.

[37] Y. Wu, M. Su, J. Chen et al., "Superior adsorption of methyl orange by $\mathrm{h}-\mathrm{MoS}_{2}$ microspheres: isotherm, kinetics, and thermodynamic studies," Dyes and Pigments, vol. 170, Article ID 107591, 2019.

[38] R. R. Karri, M. Tanzifi, M. Tavakkoli Yaraki, and J. N. Sahu, "Optimization and modeling of methyl orange adsorption onto polyaniline nano-adsorbent through response surface methodology and differential evolution embedded neural network," Journal of Environmental Management, vol. 223, pp. 517-529, 2018.

[39] V. S. Munagapati, V. Yarramuthi, and D.-S. Kim, "Methyl orange removal from aqueous solution using goethite, chitosan beads and goethite impregnated with chitosan beads," Journal of Molecular Liquids, vol. 240, pp. 329-339, 2017.
[40] H. Y. Zhu, R. Jiang, Y.-Q. Fu, J.-H. Jiang, L. Xiao, and G.-M. Zeng, "Preparation, characterization and dye adsorption properties of $\gamma$-Fe2O3/SiO2/chitosan composite," Applied Surface Science, vol. 258, no. 4, pp. 1337-1344, 2011.

[41] J. Zhang, Q. Zhou, and L. Ou, "Kinetic, isotherm, and thermodynamic studies of the adsorption of methyl orange from aqueous solution by chitosan/alumina composite," Journal of Chemical \& Engineering Data, vol. 57, no. 2, pp. 412-419, 2011.

[42] J.-H. Huang, K.-L. Huang, S.-Q. Liu, A.-T. Wang, and C. Yan, "Adsorption of Rhodamine B and methyl orange on a hypercrosslinked polymeric adsorbent in aqueous solution," Colloids and Surfaces A: Physicochemical and Engineering Aspects, vol. 330, no. 1, pp. 55-61, 2008.

[43] K. Haitham, S. Razak, and M. A. Nawi, "Kinetics and isotherm studies of methyl orange adsorption by a highly recyclable immobilized polyaniline on a glass plate," Arabian Journal of Chemistry, vol. 12, no. 7, pp. 1595-1606, 2019.

[44] R. Istratie, M. Stoia, C. Păcurariu, and C. Locovei, "Single and simultaneous adsorption of methyl orange and phenol onto magnetic iron oxide/carbon nanocomposites," Arabian Journal of Chemistry, vol. 12, no. 8, pp. 3704-3722, 2019.

[45] A. R. Agcaoili, M. U. Herrera, C. M. Futalan, and M. D. L. Balela, "Fabrication of polyacrylonitrile-coated kapok hollow microtubes for adsorption of methyl orange and $\mathrm{Cu}(\mathrm{II})$ ions in aqueous solution," Journal of the Taiwan Institute of Chemical Engineers, vol. 78, pp. 359-369, 2017.

[46] H. Y. Zhu, R. Jiang, L. Xiao, and G. M. Zeng, "Preparation, characterization, adsorption kinetics and thermodynamics of novel magnetic chitosan enwrapping nanosized $\gamma$-Fe2O3 and multi-walled carbon nanotubes with enhanced adsorption properties for methyl orange," Bioresource Technology, vol. 101, no. 14, pp. 5063-5069, 2010.

[47] M. Nitsae, A. Madjid, A. Madjid, L. Hakim, and A. Sabarudin, "Preparation of chitosan beads using tripolyphosphate and ethylene glycol diglycidyl ether as crosslinker for $\mathrm{Cr}(\mathrm{VI})$ adsorption," Chemistry \& Chemical Technology, vol. 10, no. 1, pp. 105-113, 2016. 